\title{
Enhanced osteogenic differentiation of alendronate-conjugated nanodiamonds for potential osteoporosis treatment
}

\author{
Guk Young Ahn ${ }^{1 \dagger}$, Sung-Eun Kim² ${ }^{+}$, Tae Hoon Yun ${ }^{1}$, Inseong Choi ${ }^{1}$, Daewon Park ${ }^{3}$ and Sung-Wook Choi ${ }^{1 *}$ (D)
}

\begin{abstract}
Background: Alendronate (Alen) is promising material used for bone-targeted drug delivery due to its high bone affinity and therapeutic effects on bone diseases. In addition, Alen can enhance the osteogenic differentiation of osteoblastic cell. Recently, nanodiamonds (NDs) with hardness, non-toxicity, and excellent biocompatibility are employed as promising materials for carrier systems and osteogenic differentiation. Therefore, we prepared Alenconjugated NDs (Alen-NDs) and evaluated their osteogenic differentiation performances.
\end{abstract}

Methods: Alen-NDs were synthesized using DMTMM as a coupling reagent. Morphological change of Mouse calvaria-derived preosteoblast (MC3T3-E1) treated with Alen-NDs was observed using the confocal microscope. The osteogenic differentiation was confirmed by cell proliferation, alkaline phosphatase (ALP), calcium deposition, and real-time polymerase chain reaction assay.

Results: Alen-NDs were prepared to evaluate their effect on the proliferation and differentiation of osteoblastic MC3T3-E1 cells. The Alen-NDs had a size of about $100 \mathrm{~nm}$, and no cytotoxicity at less than $100 \mathrm{\mu g} / \mathrm{mL}$ of concentration. The treatment of NDs and Alen-NDs reduced the proliferation rate of MC3T3-E1 cells without cell death. Confocal microscopy images confirmed that the treatment of NDs and Alen-NDs changed the cellular morphology from a fibroblastic shape to a cuboidal shape. Flow cytometry, alkaline phosphatase (ALP) activity, calcium deposition, and real-time polymerase chain reaction (RT-PCR) confirmed the higher differentiation of MC3T3-E1 cells treated by Alen-NDs, compared to the groups treated by osteogenic medium and NDs. The higher concentration of Alen-ND treated in MC3T3-E1 resulted in a higher differentiation level.

Conclusions: Alen-NDs can be used as potential therapeutic agents for osteoporosis treatment by inducing osteogenic differentiation.

Keywords: Alendronate, Nanodiamond, Proliferation, Osteogenic differentiation

\footnotetext{
* Correspondence: choisw@catholic.ac.kr

${ }^{\dagger}$ Guk Young Ahn and Sung-Eun Kim contributed equally to this work.

'Biomedical and Chemical Engineering, Department of Biotechnology, The

Catholic University of Korea, 43 Jibong-ro Wonmi-gu, Gyeonggi-do 14662

Bucheon-si, Republic of Korea

Full list of author information is available at the end of the article
}

(c) The Author(s). 2021 Open Access This article is licensed under a Creative Commons Attribution 4.0 International License, which permits use, sharing, adaptation, distribution and reproduction in any medium or format, as long as you give appropriate credit to the original author(s) and the source, provide a link to the Creative Commons licence, and indicate if changes were made. The images or other third party material in this article are included in the article's Creative Commons licence, unless indicated otherwise in a credit line to the material. If material is not included in the article's Creative Commons licence and your intended use is not permitted by statutory regulation or exceeds the permitted use, you will need to obtain permission directly from the copyright holder. To view a copy of this licence, visit http://creativecommons.org/licenses/by/4.0/ The Creative Commons Public Domain Dedication waiver (http://creativecommons.org/publicdomain/zero/1.0/) applies to the data made available in this article, unless otherwise stated in a credit line to the data. 


\section{Background}

Osteoporosis is a metabolic disorder that increases the risk of fractures due to decreased bone density and strength, and deterioration of bone microstructure $[1,2]$. It is difficult to know until a fracture occurs, leading to serious secondary problems of health, and even death [3, 4]. Various agents, including hormones (estrogen, calcitonin, and teriparatide) [5-7], selective estrogen receptor modulators (raloxifene and bazedoxifene) [8, 9], and bisphosphonates (alendronate, ibandronate, and zoledronate) $[10,11]$, have been studied for the treatment of osteoporosis. Among these agents, alendronate (Alen) is one of the bisphosphonates that have selective bone adsorption properties, preventing bone resorption by inhibiting osteoclastic activity, and one that is widely used in the treatment of osteoporosis [12, 13]. In addition, Alen is known to enhance the osteogenic differentiation of bone marrow stromal and osteoblastic cells [14, 15]. The currently available osteoporosis treatments are mostly conducted by oral tablets [16]. However, side effects, such as atypical fractures, atrial fibrillation, and osteonecrosis of the jaw, have occurred in oral drug delivery $[17,18]$. Therefore, to prevent potential side effects, a suitable carrier system for delivering osteoporosis drugs is needed.

Recently, nanocarriers based on liposomes, polymers, silica, metal, hydroxyapatite, and carbon-based nanomaterials have been found to be promising for the effective treatment of osteoporosis [19]. Those nanocarriers have advantages in terms of protection from transport efficiency, biodegradation, targeting, biodistribution, and so forth [20]. Among these nanomaterials, nanodiamonds (NDs) with a truncated octahedral structure have emerged as promising carbon-based nanocarriers in a variety of biomedical applications, because of their optical properties, high surface area, non-toxicity, colloidal stability, good mechanical strength, and high surface functionality [21]. Zhang et al. fabricated NDcomposited poly(L-lactic acid) scaffolds, and demonstrated their enhanced proliferation and differentiation on osteoblast through mRNA expression, suggesting the positive effect of NDs on osteoblastic differentiation [22]. Choi et al. designed Alen-modified hydroxyapatite nanoparticles and proved the capabilities of high affinities to tricalcium phosphate disk, bone-specific proliferation, and enhanced differentiation of osteoblast. The dual delivery effect of therapeutic Alen and osteoconductive hydroxyapatite showed great potential for the treatment of bone diseases [23].

We had demonstrated the bone-targeted ability of Alen-conjugated NDs (Alen-NDs) through in vivo study [24]. However, the effect of the Alen-ND on the cellular morphology and the feasibility for new bone formation were not evaluated in our previous work. Yi et al. investigated the cellular effects of gold nanoparticles (AuNPs) on the differentiation of mesenchymal stem cells (MSCs) and showed that the AuNPs promoted the osteogenic differentiation to osteoblast and inhibit adipogenic differentiation due to the mechanical stress on the cells [25]. In this work, we investigated the osteogenic differentiation effect of NDs as a functional carbon-based nanomaterial. Both the ND and Alen-ND changed the morphology of preosteoblasts and induced the transition from proliferation to differentiation, resulting in the secretion of bone-related biomarkers. To our best knowledge, it was the first report on the cellular morphological change and osteogenic differentiation of preosteoblasts by ND-based nanoparticles. We believe that Alen-NDs with the capability of inducing effective osteogenic differentiation could be a promising candidate for osteoporosis treatment.

\section{Materials and methods Materials}

Carboxyl NDs and 4-(4,6-dimethoxy-1,3,5-triazine-2-yl)4-methylmorpholinium chloride (DMTMM) were purchased from Tokyo Chemical Industry Co., Ltd. (TCI, Tokyo, Japan). Alendronate (Alen) was provided by Samjin Pharm. Co. Ltd. (Seoul, Korea). Dulbecco's Modified Eagle's Medium (DMEM), phosphate-buffered saline (PBS), and fetal bovine serum (FBS) were purchased from Welgene (Gyeongsan, Korea). Formaldehyde solution (4\%) was purchased from T\&I (Chuncheon, Korea). Cell Counting Kit-8 (CCK-8) was purchased from Dojindo Laboratories Co. Ltd. (Kumamoto, Japan).

\section{Synthesis of Alen-NDs}

Alen-NDs were synthesized by forming an amide bond using DMTMM as a coupling reagent. ND powders (200 mg) were dispersed in $50 \mathrm{~mL}$ of deionized water. For conjugation of Alen onto the surface of NDs, DMTMM (10 mg) and Alen (100 mg) were added into the aqueous NDs dispersion, and stirred for $24 \mathrm{~h}$ at $60{ }^{\circ} \mathrm{C}$, followed by centrifugation for purification with distilled water three times. The sample was then finally freeze-dried. To characterize ND-based nanoparticles, the dynamic light scattering method (Zeta-sizer Nano ZS, Malvern Instruments Ltd., Malvern, UK) was used to measure their sizes and zeta-potentials. Scanning electron microscopy (SEM, S-4800, Hitachi, Tokyo, Japan) was used to analyze their morphologies.

\section{Cell viability and proliferation}

The cell viability of mouse fibroblast (NIH/3 T3) and mouse calvaria-derived preosteoblast (MC3T3-E1) cells were evaluated after the treatment of NDs and AlenNDs. Aqueous dispersions of NDs $(100 \mu \mathrm{g} / \mathrm{mL})$ and 
Alen-NDs $(10,50$, and $100 \mu \mathrm{g} / \mathrm{mL})$ were added to each well containing $2 \times 10^{4}$ cells $/ \mathrm{mL}$ in a 96-well plate and incubated in a humidified atmosphere containing 5\% $\mathrm{CO}_{2}$ at $37^{\circ} \mathrm{C}$. The culture medium consisted of DMEM supplemented with heat-inactivated $10 \%$ fetal bovine serum (FBS) and 1\% antibiotics (penicillin and streptomycin). The number of cells was evaluated using the CCK- 8 assay with respect to time. The CCK-8 solution $(20 \mu \mathrm{L})$ was added to each well of the 96-well plates and

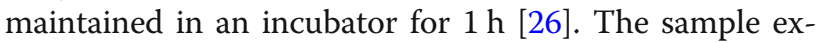
tracts were transferred to 96-well plates, and their absorbances at $450 \mathrm{~nm}$ were measured by a microplate reader (Spectra Max Plus 384, Molecular Devices, Co. Ltd., Philadelphia, USA) [27]. The cell viability (\%) was determined as the percentage of the absorbance of the treated group divided by the absorbance of the non-treated group (control) under the same condition.

Cell proliferation was measured using the CCK- 8 assay at $(1,3,5$, and 7$)$ days after cell seeding $\left(2 \times 10^{4}\right.$ cells/ $\mathrm{mL})$. Aqueous dispersions of NDs $(100 \mu \mathrm{g} / \mathrm{mL})$ and Alen-NDs (only DMEM, 10, 50, and $100 \mu \mathrm{g} / \mathrm{mL}$ ) were added to each well and cell proliferation was analyzed by the same method as in cell viability analysis.

\section{Cell morphology and differentiation}

To confirm the morphological change of MC3T3-E1 cells, the cells $\left(2 \times 10^{4}\right.$ cells $\left./ \mathrm{mL}\right)$ were cultured in an 8-well Cell Culture Slide (SPL Life Sciences, Pocheon, Korea) containing $100 \mu \mathrm{L}$ of the culture medium in an incubator. Aqueous dispersions of the only DMEM (control), NDs, and Alen-NDs $(100 \mu \mathrm{g} / \mathrm{mL})$ were added to each well and allowed to grow for 7 days. The culture slides were gently washed with PBS, fixed with formaldehyde solution (4\%) for $15 \mathrm{~min}$ at room temperature, and rinsed 3 times with PBS. The cells were then stained with 4',6-diamidino-2-phenylindole (DAPI) for $10 \mathrm{~min}$ and stained with rhodamine for $1 \mathrm{~h}$ in dark. The fluorescence was visualized by confocal microscopy (LSM710, Carl Zeiss, Oberkochen, Germany), and the cellular dimensions were analyzed using Image ${ }^{\triangleright}$ software (National Institutes of Health, Bethesda, USA).

The osteogenic differentiation was confirmed by fluorescence-activated cell sorting analysis (FACS, FACS Canto II, BD Biosciences, San Jose, USA). MC3T3-E1 cells $\left(1 \times 10^{5}\right.$ cells $\left./ \mathrm{mL}\right)$ were cultured after treatment by NDs and Alen-NDs $(100 \mu \mathrm{g} / \mathrm{mL})$ in the medium for 7 days. Then, anti-CD44, anti-CD51, and anti-CD45 antibodies (eBioscience) were treated to each well for $30 \mathrm{~min}$ on ice. After staining, cells were fixed with paraformaldehyde (2\%) and analyzed with a FACS. Data were analyzed with FlowJo software (v. 10.1, FlowJo LLC, USA).

\section{ALP activity}

To evaluate early osteogenic differentiation, MC3T3-E1 cells were seeded on a 24-well culture plate at a concentration of $1 \times 10^{5}$ cells $/ \mathrm{mL}$, and incubated in culture medium (C.M., DMEM supplemented with 10\% FBS and $1 \%$ antibiotics), osteogenic medium (O.M., C.M. supplemented with $50 \mu \mathrm{g} / \mathrm{mL}$ ascorbic acid, $10 \mathrm{nM}$ dexamethasone, and $10 \mathrm{mM}$-glycerophosphate), and culture medium containing NDs $(100 \mu \mathrm{g} / \mathrm{mL})$ or Alen-NDs $(25$, 50 , and $100 \mu \mathrm{g} / \mathrm{mL}$ ). The cells were obtained at predetermined time points of 3,7 , and 10 days. The cells were lysed using 1× RIPA (radioimmunoprecipitation assay) buffer [ $50 \mathrm{mM}$ Tris- $\mathrm{HCl}, \mathrm{pH} 7.4,150 \mathrm{mM} \mathrm{NaCl}, 0.25 \%$ deoxycholic acid, 1\% Tergitol-type-40 (NP-40), and 1 $\mathrm{mM}$ ethylenediaminetetraacetic acid (EDTA) including protease and phosphatase inhibitors (1 mM phenylmethylsulfonyl fluoride (PMSF), $1 \mathrm{mM}$ sodium orthovanadate, $1 \mathrm{mM}$ sodium fluoride, $1 \mu \mathrm{g} / \mathrm{mL}$ aprotinin, $1 \mu \mathrm{g} /$ $\mathrm{mL}$ leupeptin, and $1 \mu \mathrm{g} / \mathrm{mL}$ pepstatin)]. The cell lysates were centrifuged at $13,500 \mathrm{rpm}$ for $3 \mathrm{~min}$ at $4{ }^{\circ} \mathrm{C}$. The supernatants were incubated with $p$-nitrophenyl phosphate solution for $30 \mathrm{~min}$ at $37^{\circ} \mathrm{C}$. The reaction was stopped by the addition of $500 \mu \mathrm{L}$ of $1 \mathrm{~N} \mathrm{NaOH}$. ALP activity was determined by measuring the conversion of $p$-nitrophenyl phosphate to $p$-nitrophenol [28]. Optical density was determined by a microplate reader (Bio-Rad, Hercules, CA, USA) at a wavelength of $405 \mathrm{~nm}$.

\section{Calcium contents}

To evaluate late osteogenic differentiation, MC3T3-E1 cells were seeded at a concentration of $1 \times 10^{5}$ cells $/ \mathrm{mL}$ on a 24-well culture plate. The cells were incubated in C.M., O.M., and culture medium containing NDs. After 21 days of culture, the cells were washed with PBS, treated with $0.5 \mathrm{~N} \mathrm{HCl}$, and centrifuged at $13,500 \mathrm{rpm}$ for $1 \mathrm{~min}$. The resulting supernatant was used for calcium deposition measurement using a QuantiChrom Calcium Assay Kit (DICA-500, BioAssay Systems, Hayward, CA, USA), according to the manufacturer's instructions. The amount of calcium produced was determined at $612 \mathrm{~nm}$ by a microplate reader.

\section{Gene expression}

To evaluate the mRNA expression of the osteogenic differentiation markers (Runx-2, osteocalcin, and osteopontin), we performed a real-time polymerase chain reaction (RT-PCR). MC3T3-E1 cells $\left(1 \times 10^{5}\right.$ cells $\left./ \mathrm{mL}\right)$ were incubated in C.M., O.M., and culture medium containing NDs $(100 \mu \mathrm{g} / \mathrm{mL})$ and Alen-NDs $(25,50$, and $100 \mu \mathrm{g} /$ $\mathrm{mL}$ ) in a 24-well culture plate. After 7 and 21 days of culture, cDNA was synthesized with $1 \mu \mathrm{g}$ total RNA and oligo (dT) primer using the Superscript First-Strand Synthesis System (Bioneer Inc., Daejeon, Korea), according to the manufacturer's instructions. The following 
oligonucleotide primers were used for RT-PCR: Runx-2, (F) 5'-ATG GCA TCA AAC AGC CTC TTC AGC A3', (R) 5'-CGT GGG TTC TGA GGC GGG ACA CC3'; ALP, (F) 5' -GTG GAA GGA GGC AGA ATT GAC CA-3', (R) 5'-AGG CCC ATT GCC ATA CAG GAT GG-3'; OCN, (F) 5'-TGA GAG CCC TCA CAC TCC TC 3', (R) 5'-ACC TTTGCT GGA CTC TGC AC-3'; OPN, (F) 5'-GAG GGC TTG GTT GTC AGC-3', (R) 5'-CAA TTC TCA TGG TAG TGA GTT TTC C-3'; GAPDH, (F) 5' -ACT TTG TCA AGC TCA TTT CC-3', and (R) 5'-TGC AGC GAA CTT TAT TGA TG-3'. PCR amplification and detection were carried out on an ABI7300 Real-Time Thermal Cycler (Applied Biosystems, Foster, CA, USA) with the DyNAmo SYBR Green qPCR Kit (Finnzymes, Espoo, Finland). The relative mRNA expression levels of Runx-2, osteocalcin, and osteopontin were normalized to that of GAPDH. All results were confirmed by repeating the experiment three times.

\section{Statics}

Quantitative data are presented as the mean \pm standard deviation and comparisons were carried out using oneway ANOVA (Systat Software Inc., Chicago, IL, USA). Differences were considered statistically significant at $\left.<0.05{ }^{* * *}<0.01,{ }^{* * * *}<0.001\right)$.

\section{Result}

Figure 1a shows the synthetic process for the conjugation of Alen onto NDs using DMTMM. Fig. 1b shows that the sizes of the NDs $(94.5 \pm 2.6 \mathrm{~nm})$ and Alen-NDs $(118.8 \pm 4.5 \mathrm{~nm})$. Zeta-potentials of NDs and Alen-NDs were $-31.7 \pm 0.4$ and $-29.7 \pm 0.7 \mathrm{mV}$, respectively (Fig. 1c). Figure 1c and d show the SEM images of the NDs

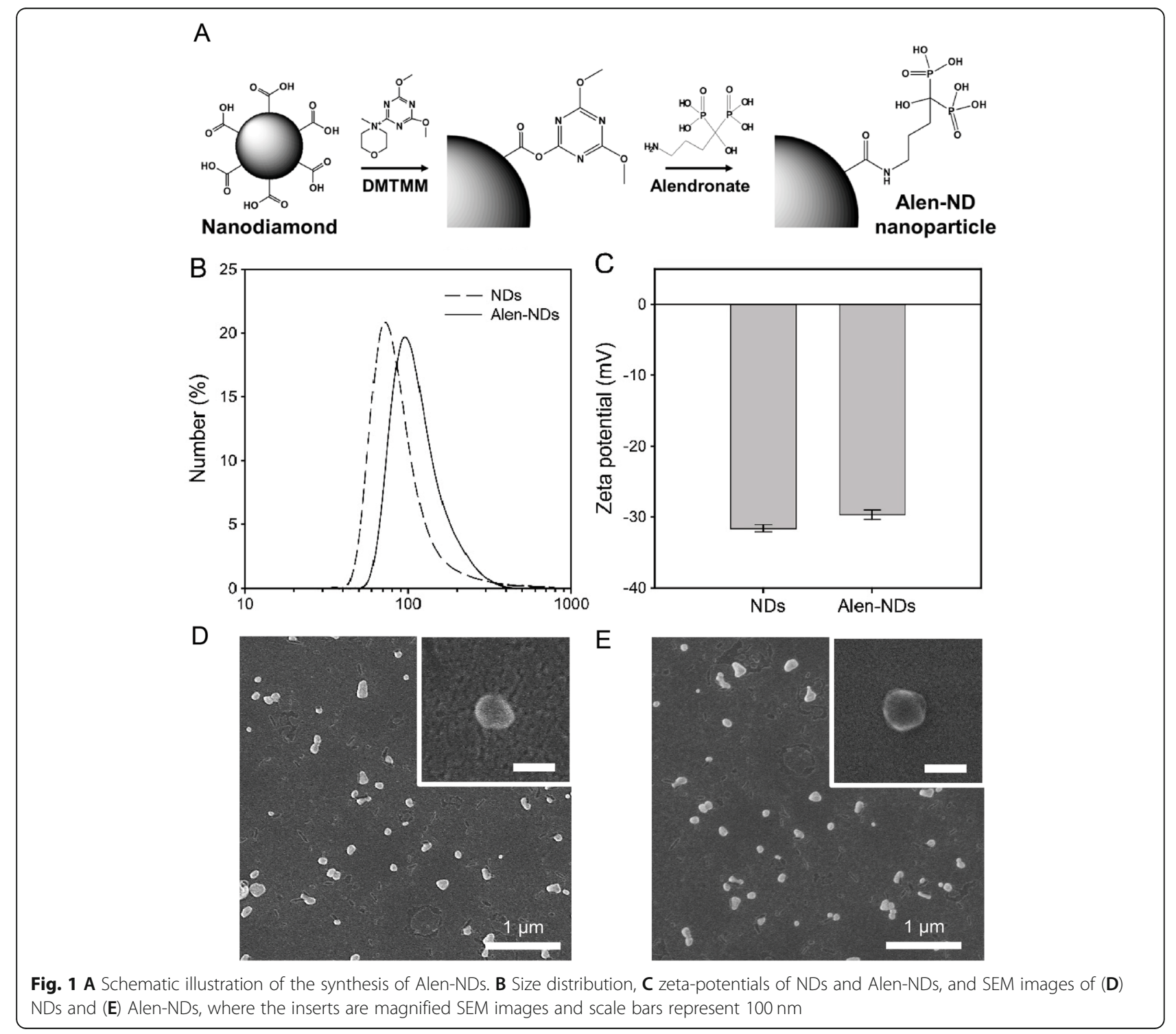


and Alen-NDs, respectively, indicating no significant change in morphology.

Figure 2 shows the viabilities of NIH/3 T3 and MC3T3-E1 cells for 24 and $48 \mathrm{~h}$ after treatment with NDs and Alen-NDs. There was no significant cytotoxicity in all samples at the concentration less than $100 \mu \mathrm{g} /$ $\mathrm{mL}$ at 24 and $48 \mathrm{~h}$. The viability of MC3T3-E1 was reduced to $82.5 \%$ at the concentration of $150 \mu \mathrm{g} / \mathrm{mL}$ at 48 $\mathrm{h}$. Therefore, all the experiments were conducted at a concentration of less than $100 \mu \mathrm{g} / \mathrm{mL}$. Figure 3 shows the cell proliferation of the NIH/3 T3 and MC3T3-E1 cells treated with NDs and Alen-NDs. Both the cells gradually proliferated over time. There were no significant differences in proliferation rates of NIH/3 T3 cells between NDs and Alen-NDs in all concentrations. However, the treatment of NDs and Alen-NDs significantly reduced the proliferation rate of MC3T3-E1 cells. The higher concentration of the Alen-ND resulted in the lower proliferation rate of the cells. At a concentration of $100 \mu \mathrm{g} / \mathrm{mL}$, NDs reduced the proliferation rate of MC3T3-E1 cells by $14.4 \%$ (4.2 and $9.0 \%$ reduction at concentrations of 10 and $50 \mu \mathrm{g} / \mathrm{mL}$, respectively) compared to the untreated group. In contrast, at a concentration of $100 \mu \mathrm{g} / \mathrm{mL}$, Alen-NDs caused reduction in the proliferation rate by $42.2 \%$ at concentration of $100 \mu \mathrm{g} / \mathrm{mL}$ (11.7 and $22.0 \%$ reduction at concentration of 10 and $50 \mu \mathrm{g} / \mathrm{mL}$ ) at 7 days.

Live/Dead staining was conducted to verify the reason for the reduction in proliferation rate (observed in Fig. 3). Figure 4 shows the Live/Dead staining images of NIH3T3 and MC3T3-E1 cells treated with NDs and Alen-NDs according to concentrations (10, 50, and $100 \mu \mathrm{g} / \mathrm{mL}$ ) at 7 days. There were few dead cells during culture with NDs and Alen-NDs, suggesting that most cells were still alive after treatment of NDs and AlenNDs less than $100 \mu \mathrm{g} / \mathrm{mL}$ of concentration.

Confocal microscopy was used to analyze the morphological change of MC3T3-E1 cells. Figure 5 shows confocal microscopy images of MC3T3-E1 cells treated by NDs and Alen-NDs, followed by dual staining. The MC3T3-E1 cells treated with NDs and Alen-NDs $(100 \mu \mathrm{g} / \mathrm{mL})$ showed more changes in cuboidal shapes from a fibroblastic shape, compared to the untreated group (control group). The width of MC3T3-E1 cells
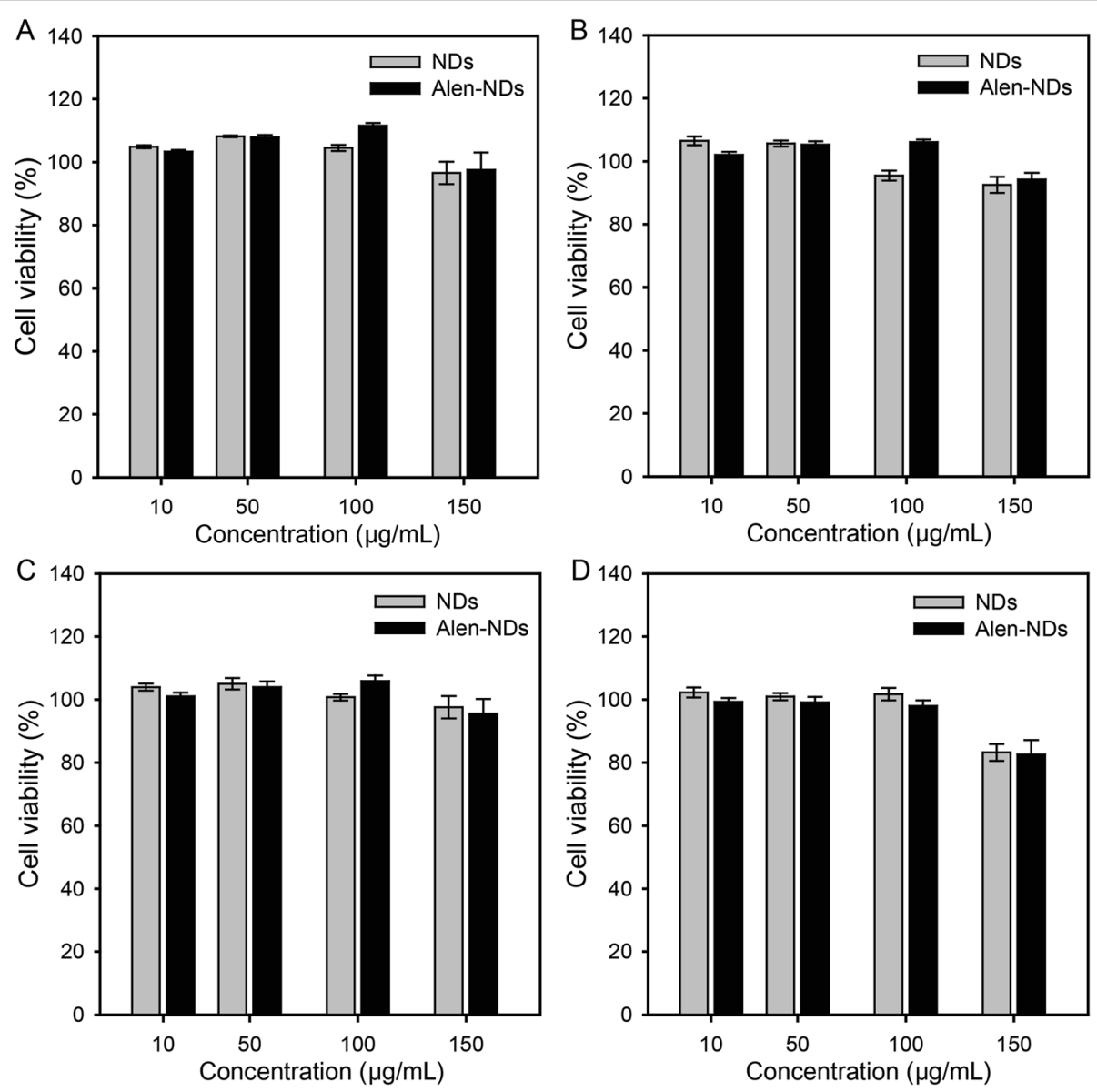

Fig. 2 Viabilities of (A, B) NIH/3 T3 and (C, D) MC3T3-E1 cells after treatment with NDs and Alen-NDs for (A, C) $24 \mathrm{~h}$ and $(\mathbf{B}, \mathbf{D}) 48 \mathrm{~h}$ 

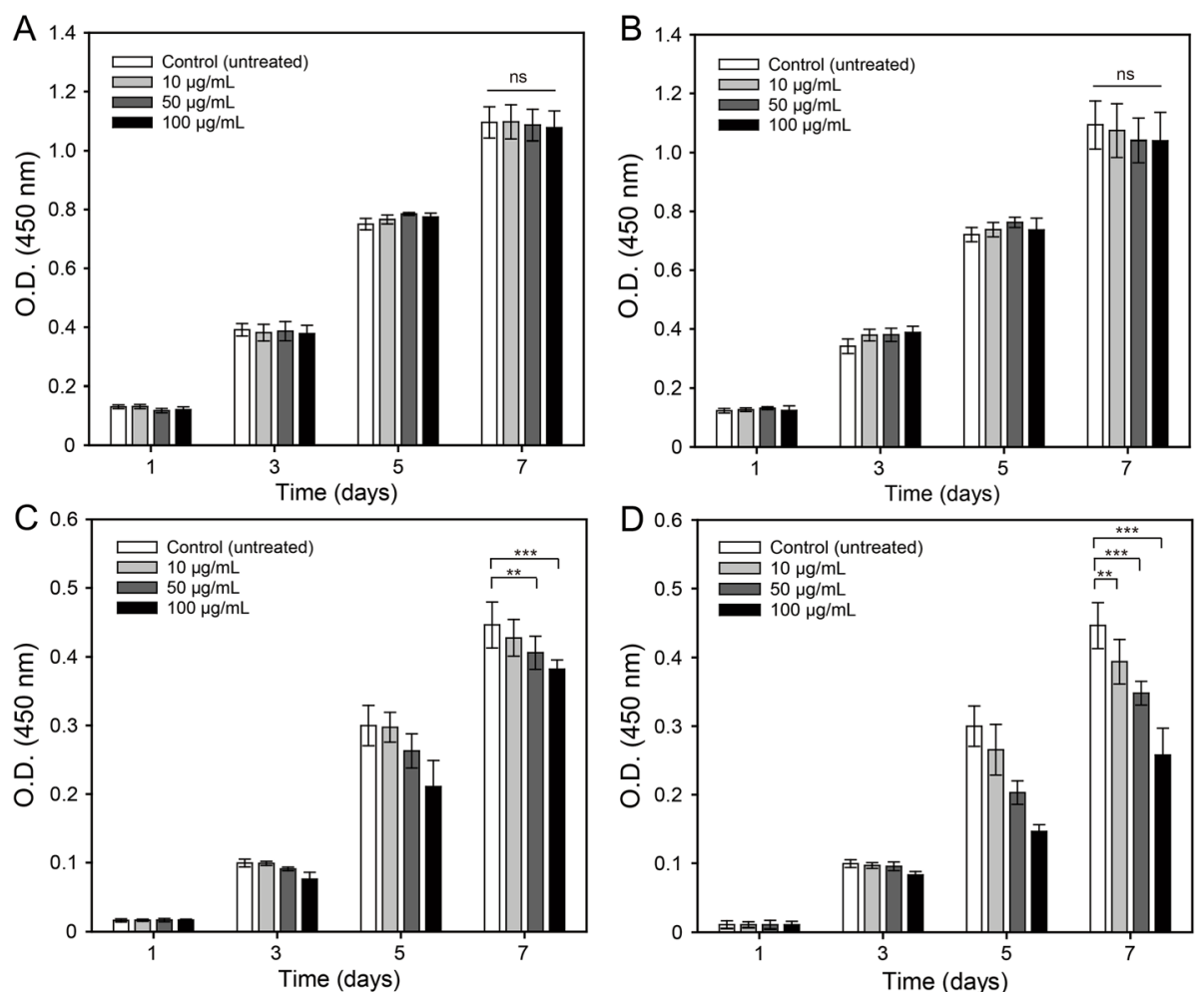

Fig. 3 Proliferation of (A, B) NIH3T3 and (C, D) MC3TE-E1 cells treated with (A, C) NDs and (B, D) Alen-NDs (10, 50, and 100 $\mu \mathrm{g} / \mathrm{mL})$ after 1, 3, 5, and 7 days (ns: no significant difference, ${ }^{* *} p<0.01,{ }^{* * *} p<0.001$ )

treated with NDs and Alen-NDs were $49.55 \pm 14.68$ and $71.00 \pm 16.97 \mu \mathrm{m}$, respectively, having significantly higher width than the control group $(18.25 \pm 3.59 \mu \mathrm{m})$. Length and cell area of NDs and Alen-NDs also significantly increased, compared to the control group (Length: $\quad 54.93 \pm 15.25 \mu \mathrm{m}$ for control, $70.68 \pm$ $12.72 \mu \mathrm{m}$ for NDs, and $76.68 \pm 19.97 \mu \mathrm{m}$ for AlenNDs. Cell area: $537.82 \pm 244.88 \mu \mathrm{m}^{2}$ for control, NDs: $1442.90 \pm 359.94 \mu^{2}$ for NDs, and 1763.06 \pm $316.12 \mu \mathrm{m}^{2}$ for Alen-NDs).

Figure 6 shows the expression of CD44, CD45, and CD51 of MC3T3-E1 cells treated with NDs and AlenNDs at a concentration of $100 \mu \mathrm{g} / \mathrm{mL}$, measured by flow cytometry. The MC3T3-E1 cells treated with NDs and Alen-NDs showed higher CD44 and CD51 expression levels than the untreated group. Besides morphological and biomarker analysis, Fig. 7a shows the ALP activity of MC3T3-E1 cells treated with NDs $(100 \mu \mathrm{g} / \mathrm{mL})$ and Alen-NDs $(25,50$, and $100 \mu \mathrm{g} / \mathrm{mL})$ after 3,7 , and 10 days, where culture medium (C.M.) and osteogenic medium (O.M.) were used as a negative and positive control, respectively. The ALP activity of MC3T3-E1 cells treated with NDs and Alen-NDs was gradually increased up to 10 days. The ALP activity of MC3T3-E1 cells treated with NDs is smaller than that of the O.M. treated group, indicating the relatively low differentiation effect of NDs. However, Alen-NDs showed a higher osteogenic differentiation than the O.M. group, even in a low concentration of $25 \mu \mathrm{g} / \mathrm{mL}$. Alen-NDs at a concentration of $100 \mu \mathrm{g} / \mathrm{mL}$ showed a 1.55 -fold higher ALP activity than that of the O.M. group at 10 days. Similar to the ALP activity results, the amounts of calcium contents treated with Alen-NDs were significantly higher than those treated with O.M. (Fig. 7b). The Alen-NDs at a concentration of $100 \mu \mathrm{g} / \mathrm{mL}$ showed 1.50 -fold higher calcium contents than those of the O.M. group at 21 days.

Figure 8 shows the mRNA expression for Runx-2, osteocalcin (OCN), and osteopontin (OPN) of MC3T3E1 cells treated with NDs $(100 \mu \mathrm{g} / \mathrm{mL})$ and Alen-NDs $(25,50$, and $100 \mu \mathrm{g} / \mathrm{mL})$ after 7 and 21 days. The Runx-2 expression at 7 days showed a similar tendency to the ALP activity and calcium contents results. The MC3T3-E1 cells treated with Alen-NDs at a concentration of $100 \mu \mathrm{g} / \mathrm{mL}$ showed a 1.66-fold higher expression level than the group treated with O.M. (Fig. 8a). At 21 days, Runx-2 expression levels were all decreased. However, there were significant differences in each group at 21 days and Alen-NDs showed the highest expression level. Figure $8 \mathrm{~b}$ and $\mathrm{c}$ show that neither the OCN nor OPN expression levels showed significant differences in each group at 


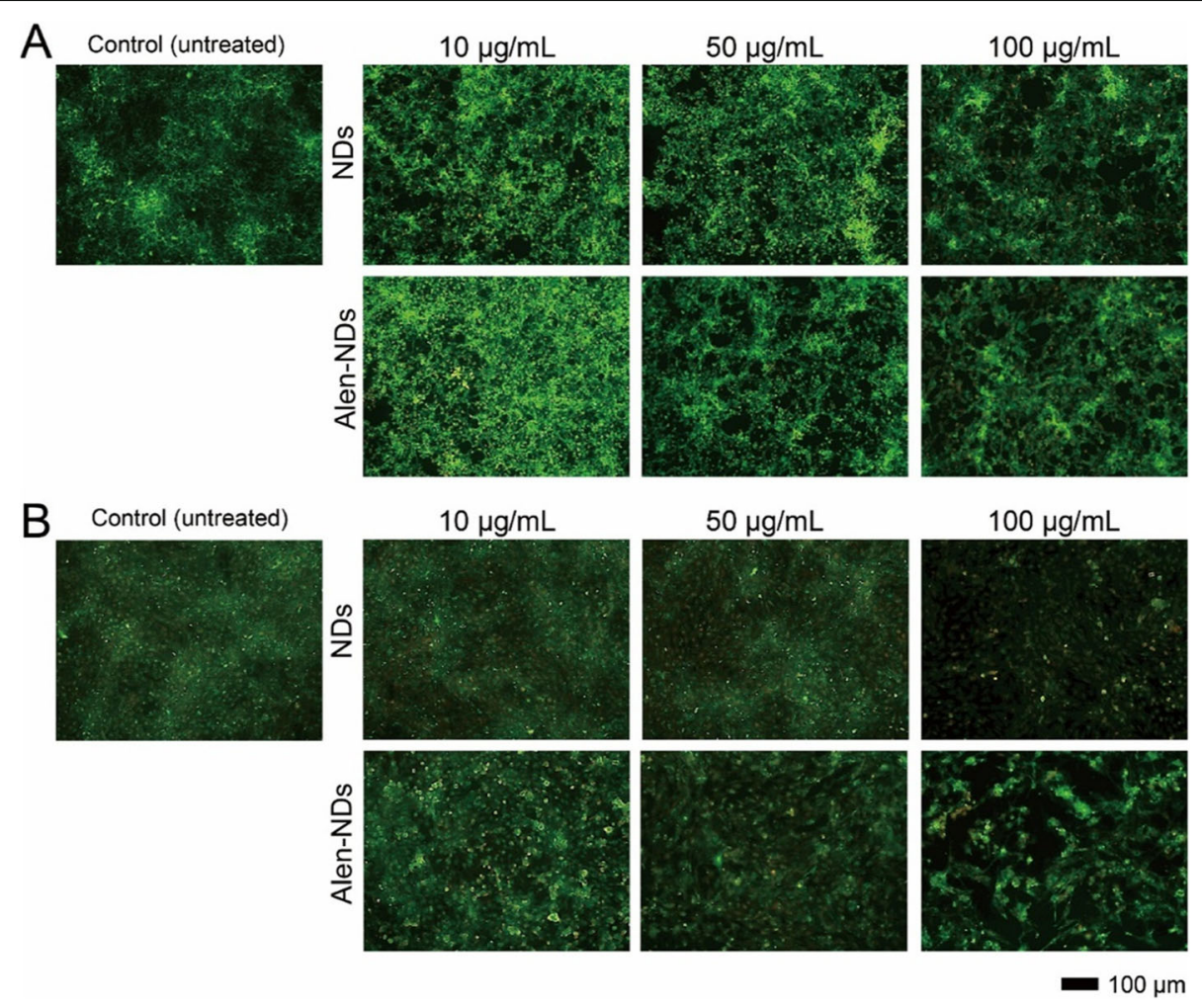

Fig. 4 Fluorescence microscopy images of (A) NIH/3 T3, and (B) MC3T3-E1 cells, treated with NDs and Alen-NDs (10, 50, and 100 $\mu \mathrm{g} / \mathrm{mL})$ for 24 h, followed by LIVE/DEAD staining (merged images)
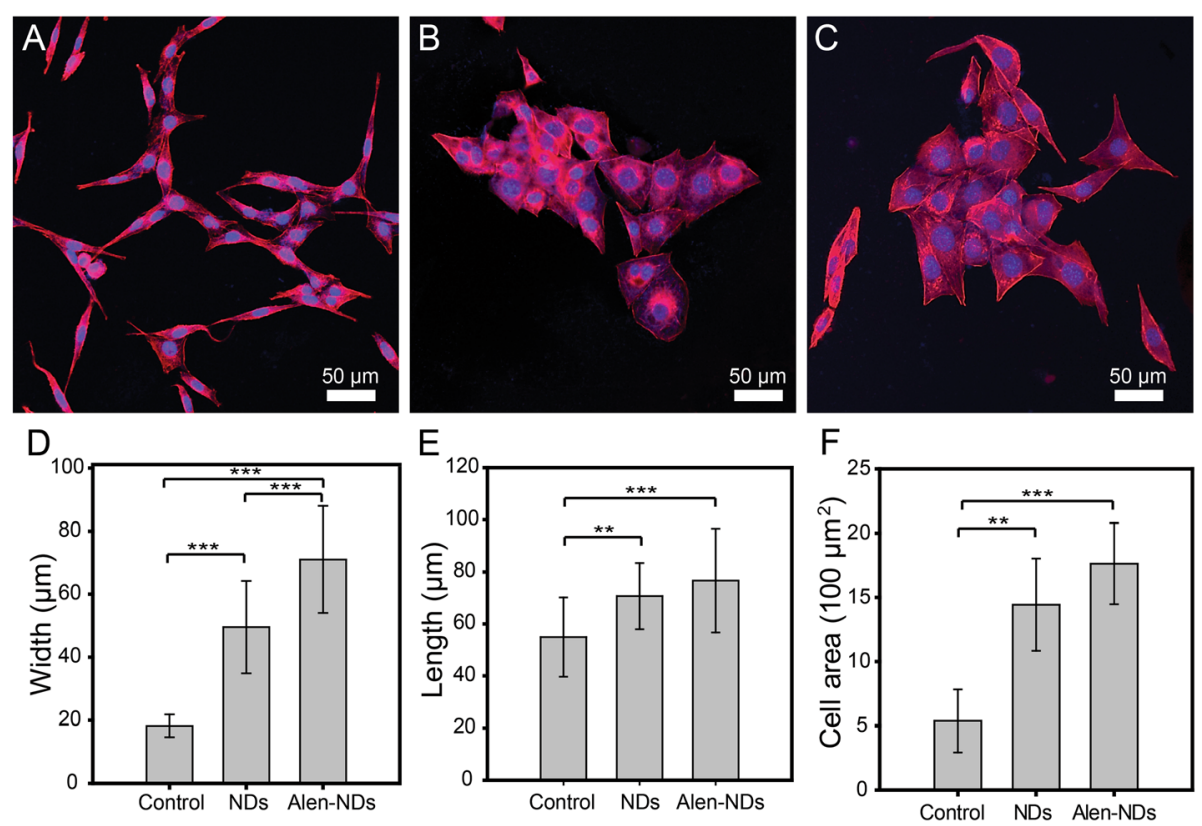

Fig. 5 Confocal microscopy images of MC3T3-E1 cells treated with (A) only DMEM (control), (B) NDs, and (C) Alen-NDs (100 $\mu \mathrm{g} / \mathrm{mL})$ at 7 days. The (D) width, (E) length, and (F) cell area of the MC3T3-E1 cells treated with only DMEM (control), NDs, and Alen-NDs $(100 \mu \mathrm{g} / \mathrm{mL})$ at 7 days $\left({ }^{* *} p<0.01,{ }^{* * *} p<0.001\right)$ 


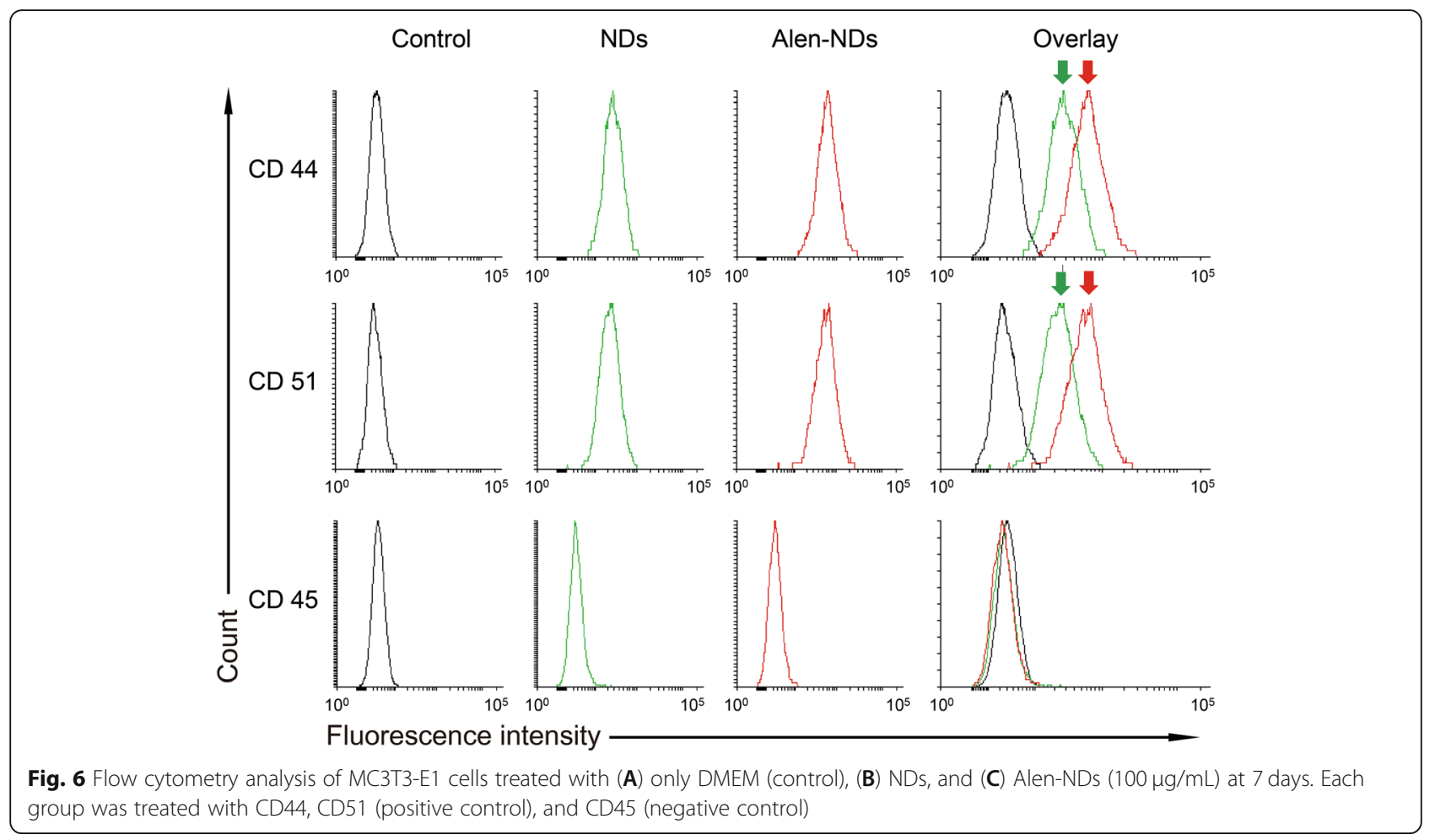

the relatively early stage (7 days). However, both the OCN and OPN expression levels were increased at 21 days. The levels of OCN and OPN expression in MC3T3-E1 cells treated with $100 \mu \mathrm{g} / \mathrm{mL}$ Alen-NDs were (1.51 and 1.54)-fold higher, respectively, than those of the O.M. group.

\section{Discussion}

In this work, Alen-NDs were synthesized to confirm the osteogenic differentiation of MC3T3-E1 cells. Alen-NDs were synthesized by forming an amide bond using DMTMM as a coupling reagent. The DMTMM activated carboxyl groups of NDs and induced an amide coupling reaction with the Alen. DMTMM was used in this chemical synthesis, as it is non-toxic, and can be completely removed from the mixture after a reaction [29]. The increase in the size of Alen-NDs might be due to Alen-conjugation on the NDs surface. It has been reported that the nanoparticles of about $100 \mathrm{~nm}$ size showed high cellular uptake efficiency in in vitro tests [30]. Despite conjugation, there was no significant difference in zeta-potential between NDs and Alen-NDs, which is due to the presence of phosphate groups of Alen [31]. Both the NDs and Alen-NDs showed a high
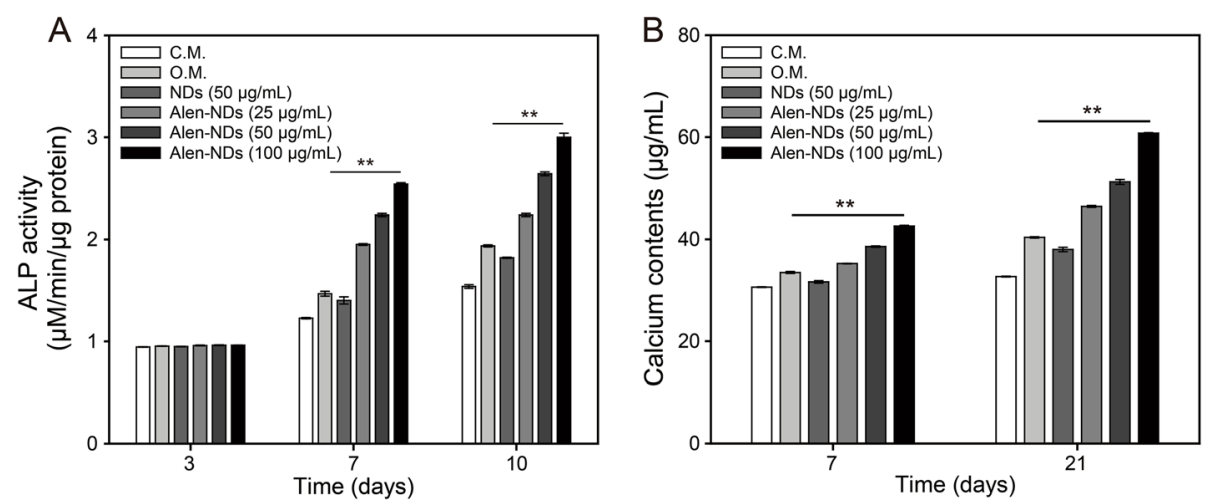

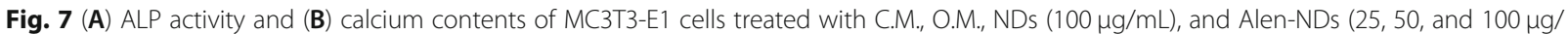
$\mathrm{mL})$ after 3,7 , and 10 days. A bar beneath the ${ }^{*}$ symbol indicates statistical significance $\left.{ }^{* *} p<0.01\right)$ across all 5 experimental groups at each time point 

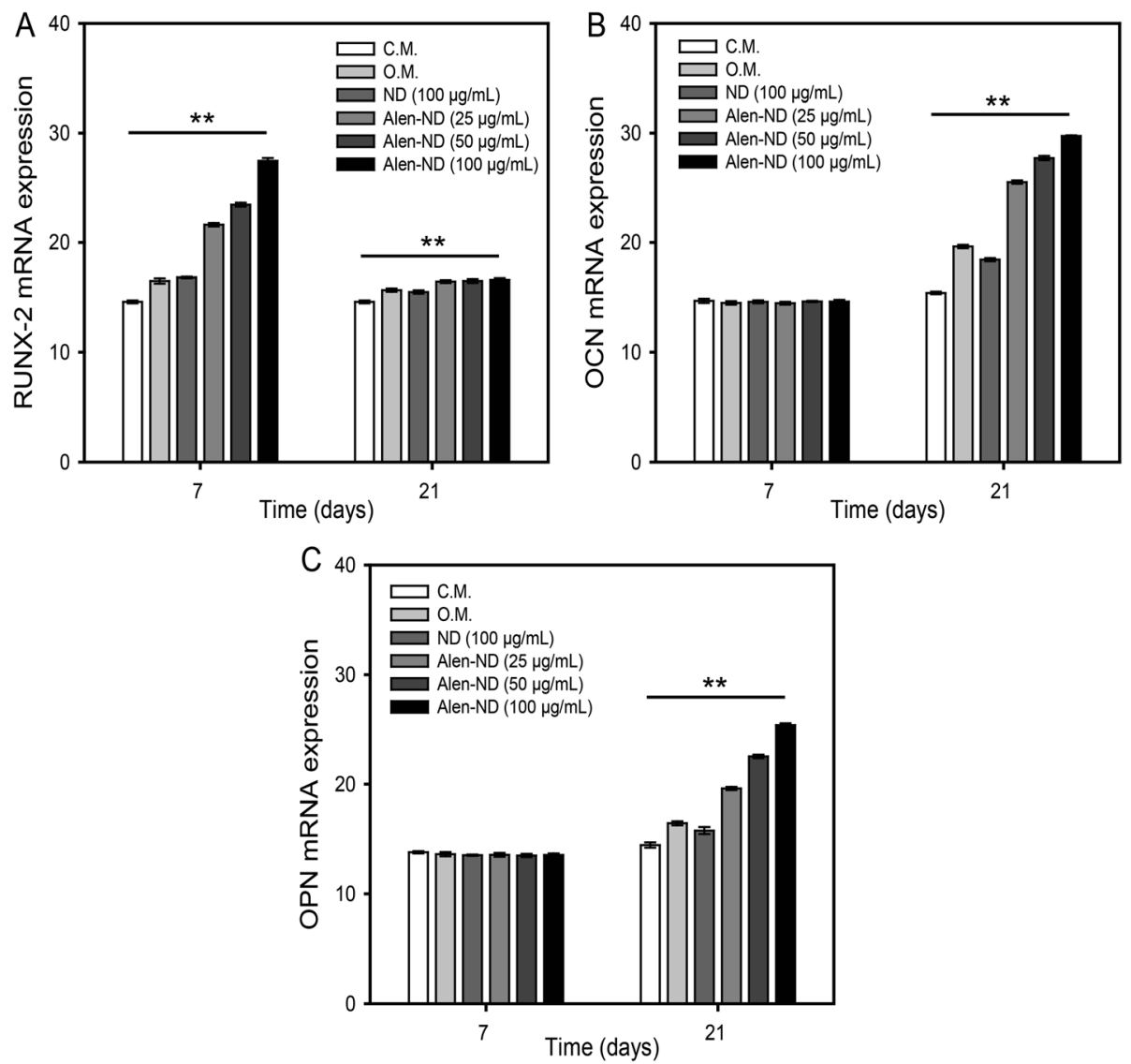

Fig. 8 RT-PCR analysis for mRNA levels of (A) RunX-2, (B) osteocalcin (OCN), and (C) osteopontin (OPN) expression of MC3T3-E1 cells treated with C.M., O.M., NDs $(100 \mu \mathrm{g} / \mathrm{mL})$, and Alen-NDs $(25,50$, and $100 \mu \mathrm{g} / \mathrm{mL})$ after 7 and 21 days. A bar beneath the *symbol indicates statistical significance $(* * 0.01)$ across all 5 experimental groups

negative charge, indicating good long-term colloidal stability. The cell viabilities of the NDs and Alen-NDs were first evaluated to determine their concentrations for in vitro study. MC3T3-E1 (osteoblast precursor) cell line was chosen as a bone model cell, whereas NIH/3 T3 cells were used as control. The viabilities of NIH/3 T3 and MC3T3-E1 cells for 24 and $48 \mathrm{~h}$ after treatment with NDs and Alen-NDs showed no significant cytotoxicity in all samples at the concentration less than $100 \mu \mathrm{g} /$ $\mathrm{mL}$. This result suggested the non-cytotoxicity of NDs. The treatment of NDs and Alen-NDs significantly reduced the proliferation rate of MC3T3-E1 cells. The Alen-ND resulted in a lower proliferation rate of the cells than NDs. Many studies have reported that differentiation reduces the proliferation rate of osteoblast [32-34]. Therefore, this result may indicate differentiation of MC3T3-E1 cells induced by Alen-NDs. At Live/ Dead staining images, there were few dead cells during culture with NDs and Alen-NDs, suggesting that reduced proliferation rate was not due to cell death. In confocal analysis, the enhanced cell area can be considered as evidence of osteoblast differentiation of MC3T3-
E1 cells induced by the up-regulation of the cytoskeleton and focal adhesion [35]. In addition, Alen-NDs caused more cell morphological changes than NDs, indicating the synergistic effect of Alen and NDs. Biomarkers, such as CD44 and CD51, were used to confirm the effect of Alen-NDs on the differentiation of MC3T3-E1 cells. The CD44 and CD51 are expressed during osteoblast differentiation and can be used as biomarkers of bone formation [36]. CD45 is not an osteoblast differentiation biomarker and served as a negative control. Alen-NDs induced more expression of CD44 and CD51 than only NDs, indicating effective osteogenic differentiation. There was no significant difference among the samples in the CD45 expression levels. It has been reported that cellular stiffness improved osteogenic differentiation [37]. Therefore, we can assume that the ND-based nanoparticles taken up by cells increase the stiffness of MC3T3-E1 cells, resulting in the induction of osteogenic differentiation. Note that NDs can enhance the expression levels of CD44 and CD45. In addition, the expression level of both the biomarkers was more increased by the treatment of Alen-NDs. ALP activity is a biomarker 
commonly used to confirm early osteoblastic differentiation $[38,39]$. The high ALP activity indicated a high osteogenic differentiation ability of Alen-NDs. These results confirm that Alen-NDs had a positive effect on the early stages of osteoblast differentiation. The calcium contents were evaluated up to 21 days since it is a latestage differentiation marker of osteoblast [40, 41]. The mRNA expression for Runx-2, OCN, and OPN was used to confirm the effect of Alen-NDs on the differentiation of MC3T3-E1 cells. Runx-2 is an essential transcription factor for osteogenic differentiation and is widely used to confirm osteoblast differentiation [42, 43]. At 21 days, Runx-2 expression levels were all decreased, since Runx-2 induces the expression of bone matrix protein genes at an early stage of osteoblast differentiation [44]. OCN and OPN are late-stage markers of osteoblast differentiation $[45,46]$. OCN is the main non-collagenous protein component of the bone extracellular matrix and OPN is an extracellular matrix cell adhesion protein, both of which are used as specific indicators of osteoblast differentiation [47]. OCN and OPN expression levels showed no significant differences in each group at the relatively early stage (7 days), because of their late-expression properties. Both the increased OCN and OPN expression levels at 21 days indicate a positive effect on the late stages of osteoblast differentiation. Taken together, these results demonstrate that Alen-NDs can effectively induce the osteogenic differentiation of MC3T3-E1 cells without cell death.

\section{Conclusions}

In summary, we successfully demonstrated the superior performance of Alen-NDs for osteogenic differentiation in terms of cell proliferation, morphological changes, FACS analysis, ALP activity, calcium contents, and mRNA expression levels. The enhanced osteogenic differentiation is attributed to the synergistic effects of Alen and NDs. Although the osteogenic differentiation effect of only NDs was slightly lower than the osteogenic medium, these NDs alone exhibited a favorable osteogenic effect and also served as good carriers to effectively deliver and internalize drugs into cells. The mechanisms on the uptake and behavior of the Alen-NDs in cells are important for understanding the fate and therapeutic efficacy of the nanoparticles, because the cellular uptake, targeting, and intracellular behaviors of nanoparticles are greatly affected by their physicochemical properties such as size, shape and surface properties. As a next goal, we are planning to conduct experiments to assess the behaviors of the AlenNDs after the cellular uptake. We believe that Alen-NDs have great potential to enhance osteogenic differentiation, ultimately increasing bone formation. Our next goal will focus on the in vivo evaluation of Alen-NDs as a therapeutic agent for osteoporosis treatment.

\section{Acknowledgements}

Not applicable.

\section{Authors' contributions}

SWC designed and coordinated the research. GYA and SEK primarily conducted research. THY, IC, and DP helped fabricate particles to cell experiments. All authors read and approved the final manuscript.

\section{Funding}

This work was supported by the Korea Medical Device Development Fund grant funded by the Korea government (the Ministry of Science and ICT, the Ministry of Trade, Industry and Energy, the Ministry of Health \& Welfare, the Ministry of Food and Drug Safety) (Project Number: 202012D21-02), the Research Fund, 2021 of The Catholic University of Korea, and the National Research Foundation of Korea (NRF) grant funded by the Korea government (MIST) (No. 2021R1A2C1003865).

\section{Availability of data and materials}

For data requests, please contact the authors.

\section{Declarations}

Ethics approval and consent to participate Not applicable.

\section{Consent for publication}

All authors have consented to the submission of this manuscript for publication.

\section{Competing interests}

The authors declare that they have no competing interests.

\section{Author details}

${ }^{1}$ Biomedical and Chemical Engineering, Department of Biotechnology, The Catholic University of Korea, 43 Jibong-ro Wonmi-gu, Gyeonggi-do 14662 Bucheon-si, Republic of Korea. ${ }^{2}$ Department of Orthopaedic Surgery and Rare Diseases Institute, Korea University Medical Centre, Guro Hospital, 80 Guro-dong, Guro-gu, Seoul 152-703, Republic of Korea. ${ }^{3}$ Department of Bioengineering, University of Colorado Denver, Anschutz Medical Campus, 12800 E. 19th Avenue, Aurora, CO 80045, USA.

Received: 17 June 2021 Accepted: 7 September 2021

Published online: 23 September 2021

\section{References}

1. Giner M, Rios MJ, Montoya MJ, Vázquez MA, Miranda C, Pérez-Cano R. Alendronate and raloxifene affect the osteoprotegerin/RANKL system in human osteoblast primary cultures from patients with osteoporosis and osteoarthritis. Eur J Pharmacol. 2011;650(2-3):682-7.

2. Tu KN, Lie JD, Wan CKV, Cameron M, Austel AG, Nguyen JK, et al. Osteoporosis: a review of treatment options. Phram Ther. 2018;43(2):92-104.

3. Fukumoto S, Matsumoto T. Recent advances in the management of osteoporosis. F1000Res. 2017;6:625.

4. Cosman F, de Beur SJ, LeBoff MS, Lewiecki EM, Tanner B, Randall S, et al. Clinician's guide to prevention and treatment of osteoporosis. Osteoporosis Int. 2014;25:2359-81.

5. Xu X, Zhang P, Li X, Liang Y, Ouyang K, Xiong J, et al. MicroRNA expression profiling in an ovariectomized rat model of postmenopausal osteoporosis before and after estrogen treatment. Am J Transl Res. 2020;12(8):4251-63.

6. Marini F, Brandi ML. Pharmacogenetics of osteoporosis. Best Pract Res Clin Endocrinol Metab. 2014;28(6):783-93.

7. Pan L, Shi X, Liu S, Guo X, Zhao M, Cai R, et al. Fluoride promotes osteoblastic differentiation through canonical Wnt/ß-catenin signaling pathway. Toxicol Lett. 2014;225(1):34-42.

8. Leder BZ, O'Dea LSL, Zanchetta JR, Kumar P, Banks K, McKay K, et al. Effects of abaloparatide, a human parathyroid hormone-related peptide analog, on bone mineral density in postmenopausal women with osteoporosis. J Clin Endocrinol Metab. 2015;100(2):697-706.

9. Masaki H, Imanishi $Y$, Naka H, Nagata $Y$, Kurajoh M, Mori K, et al. Bazedoxifene improves renal function and increases renal phosphate 
excretion in patients with postmenopausal osteoporosis. J Bone Metab. 2020;38:405-11.

10. Li D, Zhou J, Zhang M, Ma Y, Yang Y, Han X, et al. Long-term delivery of alendronate through an injectable tetra-PEG hydrogel to promote osteoporosis therapy. Biomater Sci. 2020;8:3138-46.

11. Chiba K, Yamada S, Yoda I, Era M, Yokota K, Okazaki N, et al. Effects of monthly intravenous ibandronate on bone mineral density and microstructure in patients with primary osteoporosis after teriparatide treatment: the MONUMENT study. Bone. 2021;144:115770.

12. Martins CA, Leyhausen G, Volk J, Geurtsen W. Effects of alendronate on osteoclast formation and activity in vitro. J Endod. 2015;41(1):45-9.

13. Manzano-Moreno FJ, Ramos-Torrecillas J, De Luna-Bertos E, Ruiz C, GarcíaMartínez $\mathrm{O}$. High doses of bisphosphonates reduce osteoblast-like cell proliferation by arresting the cell cycle and inducing apoptosis. J Craniomaxillofac Surg. 2015;43(3):396-401.

14. Kim HK, Kim JH, Abbas AA, Yoon TR. Alendronate enhances osteogenic differentiation of bone marrow stromal cells: a preliminary study. Clin Orthop Relat Res. 2009;467(12):3121-8.

15. Gao X, Guan M, Liu X, Xu HHK, Huang Q, Chen L, et al. Sustained delivery of growth factors and alendronate using partially demineralized dentin matrix for endogenous periodontal regeneration. Appl Mater Today. 2021;22: 100922.

16. Asafo-Adjei TA, Chen AJ, Najarzadeh A, Puleo DA. Advances in controlled drug delivery for treatment of osteoporosis. Curr Osteoporos Rep. 2016; 14(5):226-38.

17. Watts NB, Diab DL. Long-term use of bisphosphonates in osteoporosis. J Clin Endocrinol Metab. 2010;95(4):1555-65.

18. Gertz BJ, Holland SD, Kline WF, Matuszewski BK, Porras AG. Clinical pharmacology of alendronate sodium. Osteoporosis Int. 1993;3(S3):13-6.

19. Mora-Raimundo P, Manzano M, Vallet-Regí M. Nanoparticles for the treatment of osteoporosis. AIMS Bioeng. 2017;4(2):259-74.

20. Xinluan W, Yuxiao L, HueiLeng HN, Zhijun Y, Ling Q. Systemic drug delivery systems for bone tissue regeneration- a mini review. Curr Pharm Des. 2015; 21(12):1575-83.

21. Mochalin VN, Shenderova O, Ho D, Gogotsi Y. The properties and applications of nanodiamonds. Nat Nanotechnol. 2012;7:11-23.

22. Zhang Q, Mochalin VN, Neitzel I, Knoke IY, Han J, Klug CA, et al. Fluorescent PLLA-nanodiamond composites for bone tissue engineering. Biomaterials. 2011;32(1):87-94.

23. Hwang SJ, Lee JS, Ryu TK, Kang RH, Jeong KY, Jun DR, et al. Alendronatemodified hydroxyapatite nanoparticles for bone-specific dual delivery of drug and bone mineral. Macromol Res. 2016;24:623-8.

24. Ryu TK, Kang RH, Jeong KY, Jun DR, Koh JM, Kim D, et al. Bone-targeted delivery of nanodiamond-based drug carriers conjugated with alendronate for potential osteoporosis treatment. J Control Release. 2016;232:152-60.

25. Yi C, Liu D, Fong CC, Zhang J, Yang M. Gold nanoparticles promote osteogenic differentiation of mesenchymal stem cells through p38 MAPK pathway. ACS Nano. 2010;4(11):6439-48.

26. Huang Y, Li X, Lu Z, Zhang H, Huang J, Yan K, et al. Nanofiber-reinforced bulk hydrogel: preparation and structural, mechanical, and biological properties. J Mater Chem B. 2020;8:9794-803.

27. Cha SH, Lee HJ, Koh WG. Study of myoblast differentiation using multidimensional scaffolds consisting of nano and micropatterns. Biomater Res. 2017;21:1.

28. Qi S, Zheng H, Qin H, Zhai H. Development of a facile and sensitive method for detecting alkaline phosphatase activity in serum with fluorescent gold nanoclusters based on the inner filter effect. Analyst. 2020;145:3871-7.

29. D'Este M, Eglin D, Alini M. A systematic analysis of DMTMM vs EDC/NHS for ligation of amines to hyaluronan in water. Carbohydr Polym. 2014;108:23946.

30. Boncel S, Walczak K. Novel acyclic amide-conjugated nucleosides and their analogues. Nucleos Nucleot Nucl. 2009;28(2):103-17.

31. Xie G, Xu W, Ge Q. Controlling membrane ionization with bifunctional alendronates to benefit desalination through forward osmosis. Desalination. 2018;447:147-57.

32. Im Gl, Qureshi SA, Kenney J, Rubash HE, Shanbhag AS. Osteoblast proliferation and maturation by bisphosphonates. Biomaterials. 2004;25(18): 4105-15.

33. Zhang J, Wang JHC. BMP-2 mediates $\mathrm{PGE}_{2}$-induced reduction of proliferation and osteogenic differentiation of human tendon stem cells. J Orthop Res. 2012;30(1):47-52.
34. Liu D, Yi C, Zhang D, Zhang J, Yang M. Inhibition of proliferation and differentiation of mesenchymal stem cells by carboxylated carbon nanotubes. ACS Nano. 2010;4(4):2185-95.

35. Hong D, Chen HX, Yu HQ, Liang Y, Wang C, Lian QQ, et al. Morphological and proteomic analysis of early stage of osteoblast differentiation in osteoblastic progenitor cells. Exp Cell Res. 2010;316(14):2291-300.

36. Kim HK, Lee JS, Kim JH, Seon JK, Park KS, Jeong MH, et al. Bone-forming peptide-2 derived from BMP-7 enhances osteoblast differentiation from multipotent bone marrow stromal cells and bone formation. Exp Mol Med. 2017;49:e328

37. Bongiorno T, Kazlow J, Mezencev R, Griffiths S, Olivares-Navarrete R, McDonald JF, et al. Mechanical stiffness as an improved single-cell indicator of osteoblastic human mesenchymal stem cell differentiation. J Biomech. 2014;47(9):2197-204

38. Chen $\mathrm{CS}$, Chang JH, Srimaneepong V, Wen JY, Tung OH, Yang $\mathrm{CH}$, et al. Improving the in vitro cell differentiation and in vivo osseointegration of titanium dental implant through oxygen plasma immersion ion implantation treatment. Surf Coat Technol. 2020;399:126125.

39. Nakata J, Akiba Y, Nihara J, Thant L, Eguchi $\mathrm{K}$, Kato H, et al. ROCK inhibitors enhance bone healing by promoting osteoclastic and osteoblastic differentiation. Biochem Biophys Res Commun. 2020;526(3):547-52.

40. Techaniyom P, Tanurat P, Sirivisoot S. Osteoblast differentiation and gene expression analysis on anodized titanium samples coated with graphene oxide. Appl Surf Sci. 2020;526:146646

41. Sun H, Wu C, Dai K, Chang J, Tang T. Proliferation and osteoblastic differentiation of human bone marrow-derived stromal cells on akermanitebioactive ceramics. Biomaterials. 2006;27(33):5651-7.

42. Valenti MT, Carbonare LD, Donatelli L, Bertoldo F, Zanatta M, Lo CV. Gene expression analysis in osteoblastic differentiation from peripheral blood mesenchymal stem cells. Bone. 2008;43(6):1084-92.

43. Zhang Y, Su J, Yu J, Bu X, Ren T, Liu X, et al. An essential role of discoidin domain receptor 2 (DDR2) in osteoblast differentiation and chondrocyte maturation via modulation of Runx2 activation. J Bone Miner Res. 2011; 26(3):604-17.

44. Komori T. Regulation of osteoblast differentiation by transcription factors. J Cell Biochem. 2006;99(5):1233-9.

45. Bahrambeigi V, Salehi R, Hashemibeni B, Esfandiari E. Transcriptomic comparison of osteopontin, osteocalcin and core binding factor 1 genes between human adipose derived differentiated osteoblasts and native osteoblasts. Adv Biomed Res. 2012;1:8

46. Qiao $X$, Nie $Y, M a Y, C h e n ~ Y$, Cheng $R$, Yin $W$, et al. Irisin promotes osteoblast proliferation and differentiation via activating the MAP kinase signaling pathways. Sci Rep. 2016;6(1):18732

47. Kim SE, Yun YP, Lee JY, Shim JS, Park K, Huh JB. Co-delivery of plateletderived growth factor (PDGF-BB) and bone morphogenic protein (BMP-2) coated onto heparinized titanium for improving osteoblast function and osteointegration. J Tissue Eng Regen Med. 2015;9(12):E219-28.

\section{Publisher's Note}

Springer Nature remains neutral with regard to jurisdictional claims in published maps and institutional affiliations.

Ready to submit your research? Choose BMC and benefit from:

- fast, convenient online submission

- thorough peer review by experienced researchers in your field

- rapid publication on acceptance

- support for research data, including large and complex data types

- gold Open Access which fosters wider collaboration and increased citations

- maximum visibility for your research: over $100 \mathrm{M}$ website views per year

At $\mathrm{BMC}$, research is always in progress.

Learn more biomedcentral.com/submissions 